\title{
MALDI-TOF Mass Array Analysis of Nell-1 Promoter Methylation Patterns in Human Gastric Cancer
}

\author{
Changlu Gao, ${ }^{1}$ Qian Zhang, ${ }^{2}$ Deyang Kong, ${ }^{3}$ Di Wu, ${ }^{1}$ Changlei Su, ${ }^{1}$ Jinxue Tong, \\ Feng Chen, ${ }^{2}$ and Qifan Zhang ${ }^{1}$ \\ ${ }^{1}$ Department of Surgical Oncology, The Fourth Hospital of Harbin Medical University, Harbin 150010, China \\ ${ }^{2}$ Central Laboratory, School of Stomatology, Peking University, Beijing 100081, China \\ ${ }^{3}$ Department of Nephrology, First Affiliated Hospital of Harbin Medical University, Harbin 150010, China \\ Correspondence should be addressed to Qifan Zhang; qifanzhang01@126.com
}

Received 21 April 2014; Revised 10 October 2014; Accepted 6 November 2014

Academic Editor: Haiteng Deng

Copyright (C) 2015 Changlu Gao et al. This is an open access article distributed under the Creative Commons Attribution License, which permits unrestricted use, distribution, and reproduction in any medium, provided the original work is properly cited.

\begin{abstract}
Mass spectrometry (MS) enables rapid and sensitive qualitative and quantitative analyses of biomolecules (proteins, peptides, oligosaccharides, lipids, DNA, and RNA), drugs, and metabolites. MS has become an essential tool in modern biomedical research, including the analysis of DNA methylation. DNA methylation has been reported in many cancers, suggesting that it can be utilized as an early biomarker to improve the early diagnosis rate. Using matrix-assisted laser desorption/ionization time-of-flight MS and MassCLEAVE reagent, we compared Nell-1 hypermethylation levels among tumor tissues, paracarcinoma tissues, and normal tissues from gastric cancer patients. Almost $80 \%$ of the $\mathrm{CpG}$ sites in the amplicons produced were covered by the analysis. Our results indicate a significant difference in methylation status between gastric cancer tissue (a higher level) and normal tissue. The same trend was identified in gastric cancer tissue versus paracarcinoma tissue. We also detected lower relative expression of Nell-1 by real-time PCR. Furthermore, immunohistochemical analyses revealed that Nell-1 staining was less intense in cancer tissue relative to normal tissue and that the tumor cells had spread to the muscle layer. These findings may serve as a guide for the early diagnosis of gastric cancer.
\end{abstract}

\section{Introduction}

Gastric cancer is one of the most common malignant tumors and the second leading cause of cancer-related deaths worldwide. Indeed, gastric cancer has one of the highest mortality rates of all cancer types and a high incidence in Asia [1]. Nearly three-quarters of cases occur in developing countries, and almost half of all cases occur in East Asia, mainly in China [2]. Because gastric cancer is an aggressive disease with nonspecific early symptoms, it is typically diagnosed only at an advanced stage $[3,4]$.

There are many established treatments for gastric cancer [3], of which surgery remains the most important for patients without major metastasis [5]. However, despite progress in surgical techniques, the overall 5 -year survival rate for gastric cancer patients is low while the cost of treatment is high [6]. To improve the early diagnosis rate, the identification of biomarkers of gastric cancer is important [7]. Like other cancers, gastric cancer is a complex and heterogeneous disease. The development and progression of gastric cancer is associated with epigenetic mechanisms, especially DNA methylation $[8,9]$. Epigenetic alterations such as changes in DNA methylation and histone acetylation/methylation are common in many cancers [10].

The best characterized mechanism is transcriptional silencing events, associated with hypermethylation of the promoter regions of genes that regulate important cell functions [11]. DNA methylation and related chromatin changes are important processes in the regulation of gene expression. Studies of various types of cancer have demonstrated the relevance of these regulatory changes. Promoter hypermethylation of tumor suppressor and tumor-related genes, including APC, $h M L H 1, R U N X 3, C A C N A 2 D 3, D K K$ 3, Cystatin, CBS, GPX3, and MYO1A, has also been observed 
in gastric cancer [12-20]. Gene promoter hypermethylation has been examined by methylation-specific PCR (MSP) and bisulfite genomic sequencing (BGS) in human gastric cancer tissues.

The Nell-1 gene has been mapped to chromosome 11p15 [21]; the high prevalence of Nell-1 promoter methylation in colon cancer suggests a role for inactivation of the gene in colon tumorigenesis. Additionally, Nell-1 is a candidate tumor suppressor gene [22]. Nell-1 promoter hypermethylation is a common, tissue-specific event in human esophageal adenocarcinoma (EAC), and it is a potential biomarker of a poor prognosis in early-stage EAC [23]. Based on these findings, we hypothesized that Nell-1 is inactivated via promoter hypermethylation in human gastric cancer and that this modification may be used as a biomarker for early detection of the disease.

Mass spectrometry (MS) can discriminate between methylated and nonmethylated samples and identify differentially methylated sites with rapidness and accuracy. Matrix-assisted laser desorption/ionization time-of-flight (MALDI-TOF) MS and the MassCLEAVE reagent (Sequenom, San Diego, CA) are used for the high-throughput quantitative analysis of DNA methylation status in the Sequenom EpiTYPER assay $[24,25]$. The utility of this method for quantifying methylated and unmethylated DNA molecules was confirmed by the Sequenom group [26].

To assess whether Nell-1 is inactivated via promoter hypermethylation in human gastric cancer, we investigated the methylation status of the Nell-1 promoter in 75 samples from 25 patients using MALDI-TOF MS. Our results show that Nell-1 promoter hypermethylation is a common event in gastric cancer.

\section{Materials and Methods}

2.1. Sample Collection. In the current study, 25 gastric cancer tissues, 25 paracarcinoma tissues $(3 \mathrm{~cm}$ from the tumor margin), 25 normal tissues, and 25 formalin-fixed paraffin wax-embedded gastric cancer tissues and normal tissues were collected from 25 gastric cancer patients who were diagnosed and underwent surgery at the Fourth Affiliated Hospital, Harbin Medical University (Harbin, China), between April and September of 2012. The patients' characteristics are shown in Table 1. All primary gastric cancers were evaluated according to the criteria set forth in the 7 th edition of the American Joint Committee on Cancer Staging Manual. The diagnosis of primary gastric cancer was confirmed by hematoxylin and eosin ( $\mathrm{H} \& \mathrm{E})$ staining. The "normal" gastric tissues in this study were histologically verified to have no neoplastic changes.

Fresh tissue samples were obtained during resection surgery, immediately snap-frozen in liquid nitrogen, and stored at $-80^{\circ} \mathrm{C}$ until they were used for DNA extraction. In this study, none of the patients received chemotherapy or radiation therapy before surgery. The primary gastric cancer tissue, tissue adjacent to the gastric cancer, and normal tissue from each patient were allocated to the gastric, paracarcinoma, and normal groups, respectively.
TABLE 1: The clinical characteristics of study subjects.

\begin{tabular}{|c|c|c|c|c|}
\hline $\mathrm{GC}^{\mathrm{a}}$ & Gender & Age (year) & Differentiation & $\mathrm{AJCC}^{\mathrm{b}}$ stage \\
\hline GC01 & Male & 76 & Poor & III \\
\hline GC02 & Female & 59 & Poor & I \\
\hline GC03 & Male & 60 & Moderate/poor & III \\
\hline GC04 & Male & 48 & Poor & III \\
\hline GC05 & Male & 77 & Moderate & II \\
\hline GC06 & Female & 69 & Poor/mucinous & III \\
\hline GC07 & Male & 49 & Poor/mucinous & III \\
\hline GC08 & Female & 58 & Moderate/poor & II \\
\hline GC09 & Male & 54 & Poor & I \\
\hline GC10 & Female & 70 & Moderate/poor & III \\
\hline GC11 & Male & 52 & Moderate & II \\
\hline GC12 & Male & 57 & Poor/mucinous & III \\
\hline GC13 & Female & 52 & Poor/mucinous & II \\
\hline GC14 & Male & 70 & Moderate/poor & II \\
\hline GC15 & Male & 65 & Moderate/poor & III \\
\hline GC16 & Male & 58 & Poor & II \\
\hline GC17 & Male & 58 & Moderate/poor & II \\
\hline GC18 & Female & 71 & Poor & III \\
\hline GC19 & Female & 55 & Poor & III \\
\hline GC20 & Female & 58 & Poor & III \\
\hline GC21 & Female & 64 & Poor & III \\
\hline GC22 & Male & 71 & Moderate & I \\
\hline GC23 & Male & 50 & Poor/mucinous & III \\
\hline GC24 & Female & 76 & Moderate/poor & III \\
\hline GC25 & Female & 55 & Moderate & $\mathrm{I}$ \\
\hline
\end{tabular}

${ }^{\mathrm{a}} \mathrm{GC}$ : gastric cancer; ${ }^{\mathrm{b}}$ AJCC: the American Joint Committee on Cancer.

All participants provided informed consent prior to their participation in the study. All procedures were approved by the ethics committees of the hospitals involved.

2.2. Immunohistochemistry (IHC) and HљE Staining. Formalin-fixed, paraffin wax-embedded gastric cancer tissues and normal tissues were used for IHC and H\&E staining. For IHC, tissues were fixed in $10 \%$ methanol/buffered formalin for $12 \mathrm{~h}$ and were processed routinely. The paraffin waxembedded sections $(4 \mu \mathrm{m})$ were immersed in xylene and rehydrated through an ethanol series. Endogenous peroxidase activity was blocked by incubating the sections in $3 \%$ $\mathrm{H}_{2} \mathrm{O}_{2}$ for $15 \mathrm{~min}$. After washing with phosphate-buffered saline (PBS), the sections were subsequently submerged in EDTA ( $\mathrm{pH}$ 9) and exposed to microwave heating for antigen retrieval, followed by $3 \mathrm{~min}$ of treatment in a prewarmed pressure cooker with antigen retrieval citrate buffer $(\mathrm{pH}$ 6.8). Following depressurization, cold water was poured into the cooker for $10 \mathrm{~min}$. The sections were then washed three times with PBS and incubated in goat serum for $20 \mathrm{~min}$. The slides were immersed in anti-Nell-1 rabbit polyclonal antibodies for $1 \mathrm{~h}$. After washing with PBS, the slides were incubated with horseradish peroxidase-conjugated antirabbit antibodies for $1 \mathrm{~h}$. The slides were then examined under a microscope. 
TABLE 2: The primer sequences of Nell-1 and GAPDH genes.

\begin{tabular}{lrr}
\hline Human gene & Forward primer sequence $\left(5^{\prime} \rightarrow 3^{\prime}\right)$ & Reverse primer sequence $\left(5^{\prime} \rightarrow 3^{\prime}\right)$ \\
\hline Nell-1 & GCTTTGGGATGGACCCTGAC & GAAATAAAAATGCTTTGCTGGC \\
GAPDH & GTCTCCTCTGACTTCAACAGCG & ACCACCCTGTTGCTGTAGCC \\
\hline
\end{tabular}

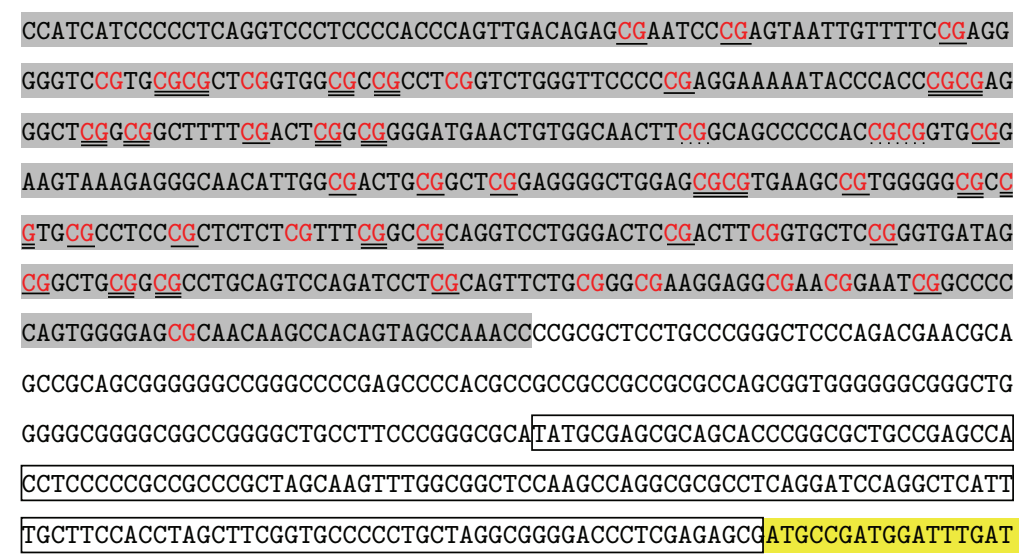

(a)

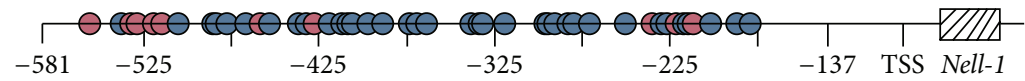

Product: 445 bp ( -581 to -137$)$ with coverage: 38

Covered

Not covered

(b)

Figure 1: Amplicon size and locations of informative CpG sites in amplicons of the Nell-1 gene. (a) The sequences of targeted gene. The amplified region was colored in gray. Transcription start sequences were labeled in frame and transcription sites were labeled in yellow. CpG sites in amplicons appear in red and single line represented separate detection. Double line showed testing with the adjacent site. Point line showed adjacent three-site testing. No line showed that CpG sites cannot be detected in amplified sequences. (b) The amplicon map and the locations of CpG sites.

2.3. DNA Extraction. For DNA extraction, frozen tissues were obtained and reviewed to confirm that the tumor content was $>80 \%$ of the section area. DNA was extracted from the frozen tissues using a QIAamp DNA Mini Kit (Qiagen AG, Basel, Switzerland) following the manufacturer's protocol; the DNA samples were dissolved in a final volume of $100 \mu \mathrm{L}$. The quantity of DNA (A260/A280) in each sample was measured using a NanoDrop 2100 spectrophotometer before sequencing (Thermo Fisher Scientific, Waltham, MA).

2.4. Real-Time PCR Analysis. Total RNA was extracted from normal and gastric cancer tissues using TRIZOL reagent (Invitrogen, Carlsbad, CA). Agarose gel electrophoresis and a NanoDrop 2000 spectrophotometer (Thermo Fisher Scientific) were employed to assess the quality and concentration of RNA. A total of $1 \mu \mathrm{g}$ of high-quality RNA was reversetranscribed to first-strand cDNA with Superscript FirstStrand Synthesis SuperMix (Invitrogen). Real-time PCR was conducted with SYBR Green Master mix (Applied Biosystems, Foster City, CA). The reaction $\left(95^{\circ} \mathrm{C}\right.$ for $15 \mathrm{~s}$ and $60^{\circ} \mathrm{C}$ for $1 \mathrm{~min}$ ) was run using the ABI PRISM 7500 Real-Time PCR System (Applied Biosystems) with relative expression analyzed by the $2^{-\Delta \Delta C t}$ method. The sequences of the primers used to amplify Nell-1 and the control gene GAPDH are listed in Table 2.

2.5. Primer Design and PCR Using the Sequenom MassARRAY System. The primers designed for Nell-1 covered those regions with the most $\mathrm{CpG}$ sites. Most selected amplicons were located in the promoter region, from -581 to -137 , relative to the transcription start site (Figure 1). The primers were designed using EpiDesigner [18]. For amplification, the reverse primer had a T7-promoter tag added, and the forward primer had a 10-mer tag sequence added to balance the PCR primer lengths (F: aaagagagGGTTTGGTTATTGTGGTTTGTTG and R: cagtaatacgactcactatagggagaaggctAACCATCATCCCCCTCAAAT). Genomic DNA was treated with bisulfite using an EpiTect Bisulfite Kit (Qiagen AG). The bisulfite-treated genomic DNA was then amplified under the following conditions: initial denaturation, $94^{\circ} \mathrm{C}$ for $4 \mathrm{~min}$, then 45 cycles of $94^{\circ} \mathrm{C}$ for $20 \mathrm{~s}, 56^{\circ} \mathrm{C}$ for $30 \mathrm{~s}$, and $72^{\circ} \mathrm{C}$ for $1 \mathrm{~min}$, followed by $3 \mathrm{~min}$ at $72^{\circ} \mathrm{C}$. The products were stored at $4^{\circ} \mathrm{C}$ for further analysis.

2.6. In Vitro Transcription and T-Cleavage (RNase A Digestion) Assay. Shrimp alkaline phosphatase (SAP; Sequenom) 
TABLE 3: MALDI-TOF MS analysis of CpG sites in amplicons of the Nell-1 gene.

\begin{tabular}{cccccc}
\hline Gene & Amplicon size (bp) & $\begin{array}{c}\text { Total number of CpG } \\
\text { sites in amplicon }\end{array}$ & $\begin{array}{c}\text { Number of analyzed CpG } \\
\text { sites in amplicon }\end{array}$ & $\begin{array}{c}\text { Number of analyzed CpG sites in amplicon } \\
\text { Single sites }\end{array}$ & $\begin{array}{c}\text { Composite sites } \\
\text { Nell-1 }\end{array} 4^{4}$ \\
\hline
\end{tabular}
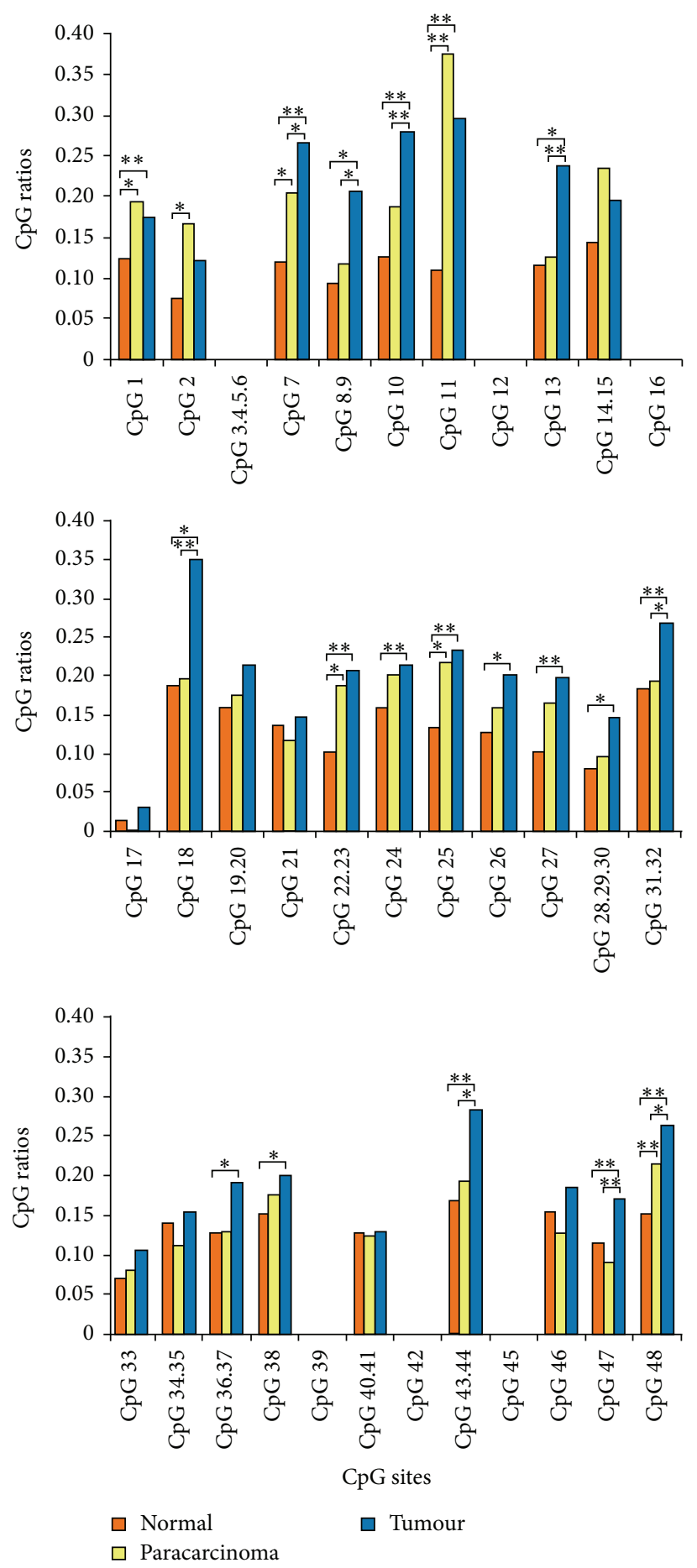

FIGURE 2: CpG ratios of CpG sites in the Nell-1 gene covered and not covered by MALDI-TOF MS analysis. Error bars and comparisons among tumour tissues, paracarcinoma tissues, and normal tissues are shown. 
was used to remove unincorporated dinucleotide triphosphates (dNTPs). The components were $1.7 \mu \mathrm{L}$ of RNase-free $\mathrm{ddH}_{2} \mathrm{O}$ and $0.3 \mu \mathrm{L}$ of SAP combined with the above PCR products. The mixture was incubated at $37^{\circ} \mathrm{C}$ for $20 \mathrm{~min}$, $85^{\circ} \mathrm{C}$ for $5 \mathrm{~min}$, and then at $4^{\circ} \mathrm{C}$ indefinitely. Using $\mathrm{T} 7$ R\&DNA polymerase (Epicentre, Madison, WI), thymidine triphosphate was incorporated into the PCR product, finishing the transcription reaction. Ribonucleotides and dNTPs were used at concentrations of 1 and $2.5 \mathrm{mmol} / \mathrm{L}$, respectively. RNase A (Sequenom) was added to the same reaction to cleave the transcripts (T-cleavage assay). The reaction mixture was incubated at $37^{\circ} \mathrm{C}$ for $3 \mathrm{~h}$. To remove the phosphate backbone, the $\mathrm{T}$-cleavage/RNase $\mathrm{A}$ assay reaction products were diluted with $20 \mu \mathrm{L}$ of RNase-free $\mathrm{H}_{2} \mathrm{O}$ and mixed with Clean Resin (Sequenom) before performing MS.

2.7. Mass Spectrometry. The entire RNase A and clean resintreated product was robotically dispensed onto silicon matrix preloaded chips (SpectroCHIP; Sequenom) and mass spectra were collected using a MassARRAY Compact MALDI-TOF Analyzer (Sequenom). The mass spectra methylation ratios were generated using EpiTYPER (ver. 4.0; Sequenom).

2.8. Statistical Methods. The data were analyzed using the SPSS software (ver. 17 for Windows; IBM, Armonk, NY). An analysis of variance (ANOVA) was used to identify significant differences in methylation rates among the samples. All $P$ values were two-sided; $P<0.05$ was considered to indicate statistical significance.

\section{Results and Discussion}

Increasing numbers of cancer deaths are projected to occur in Asia; this trend can be combatted by expanding knowledge of cancer control and the underlying genetic mechanisms [2]. Although much has been learned about the genetic causes of cancer, the details remain unclear [27].

In a previous study, MSP and BGS were used to analyze promoter methylation [28]; however, these methods have similar disadvantages. For this reason, Sequenom created a high-throughput quantitative assay for DNA methylation using MALDI-TOF MS and MassCLEAVE reagent. This method is highly accurate with regard to specific methylation sites, and it enables both quantitative assessment of methylation levels and analysis of multiple methylation sites [16, 24, 25, 29].

In this study, we analyzed the methylation patterns of the Nell-1 gene in 25 gastric cancer tissue samples, 25 tissues adjacent to gastric cancer, and 25 normal samples. The Nell1 sequences analyzed contained CpG-rich regions. In total, $48 \mathrm{CpG}$ sites per sample were analyzed. More than $50 \%$ of the CpG sites in Nell-1 were detected in amplicons, and almost $80 \%$ of the CpG sites in the amplicons were used in our analysis (Table 3 ).

The three types of samples showed different methylation levels at the various CpG sites in Nell-1. An ANOVA demonstrated significant differences in the methylation levels of Nell-1 between the gastric cancer and normal samples $(P<$

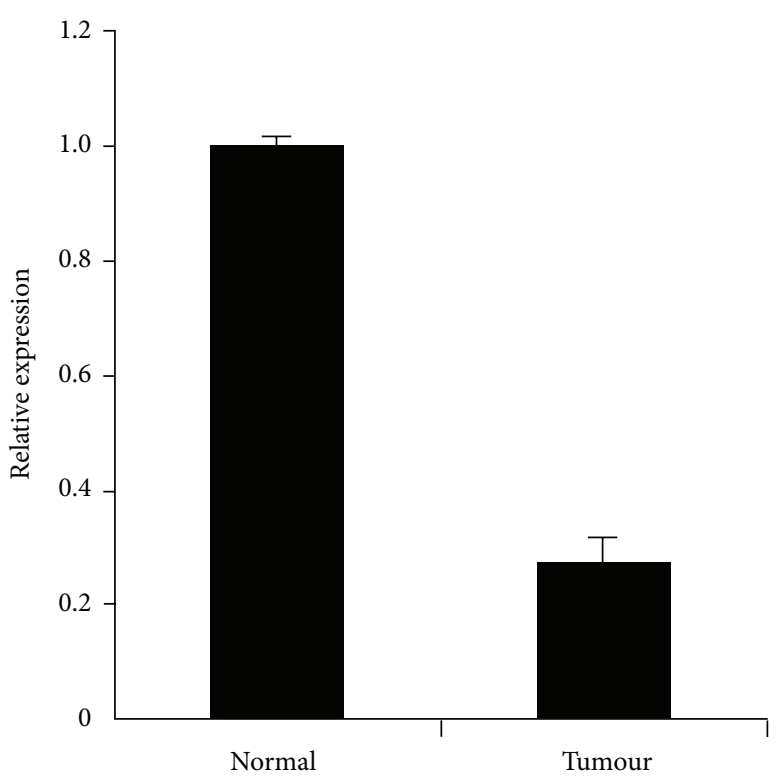

Figure 3: Nell-1 mRNA expression analysis. Quantitative polymerase chain reaction (qPCR) was performed to identify the mRNA expression of Nell-1 in normal tissues and tumour tissues.

0.05 at $8 \mathrm{CpG}$ sites and $P<0.01$ at $11 \mathrm{CpG}$ sites). Additionally, significant differences were detected between the gastric cancer and paracarcinoma samples $(P<0.05$ at five $\mathrm{CpG}$ sites and $P<0.01$ at four $\mathrm{CpG}$ sites). However, there was no significant difference between the paracarcinoma and normal samples (eight $\mathrm{CpG}$ sites with $P<0.05$ ). Also, the gastric cancer samples had higher degrees of methylation relative to the normal samples (Figure 2). The abnormal methylation of DNA is an early event in carcinogenesis and can serve as a biomarker for early detection [30]. In this study, we demonstrated that the methylation level of Nell-1 is an important issue in gastric cancer. This finding may be useful in the earliest stages of clinical disease. However, before considering the methylation status of the Nell-1 promoter as a biomarker in gastric cancer and normal tissues, further research is needed. In cancer patients, promoter hypermethylation has some prognostic value. It has been reported that Nell-1 binds to a specific membrane protein (APR3) to mediate the downregulation of cyclin D1 [31]. Based on a functional analysis of cell proliferation and osteoblast differentiation, APR3 binding may be the mechanism by which Nell-1 promotes osteoblast differentiation [32]. Thus, Nell-1, as a suppressor gene may play a role in cancer metastasis.

We also found that the transcription and translation of Nell-1 were decreased in the gastric cancer samples compared to the normal samples. This may be explained by the fact that the methylation of a gene can reduce its expression. Quantitative PCR showed that the mRNA expression of Nell1 in the gastric cancer tissues was decreased threefold compared with that in the normal tissues (Figure 3). As expected, immunohistochemical analyses of gastric cancer samples showed a lower intensity of Nell-1 staining and that the cancer cells had spread to the muscle layer (Figure 4). The malignant transformation of gastric cells occurs via a multistep process 

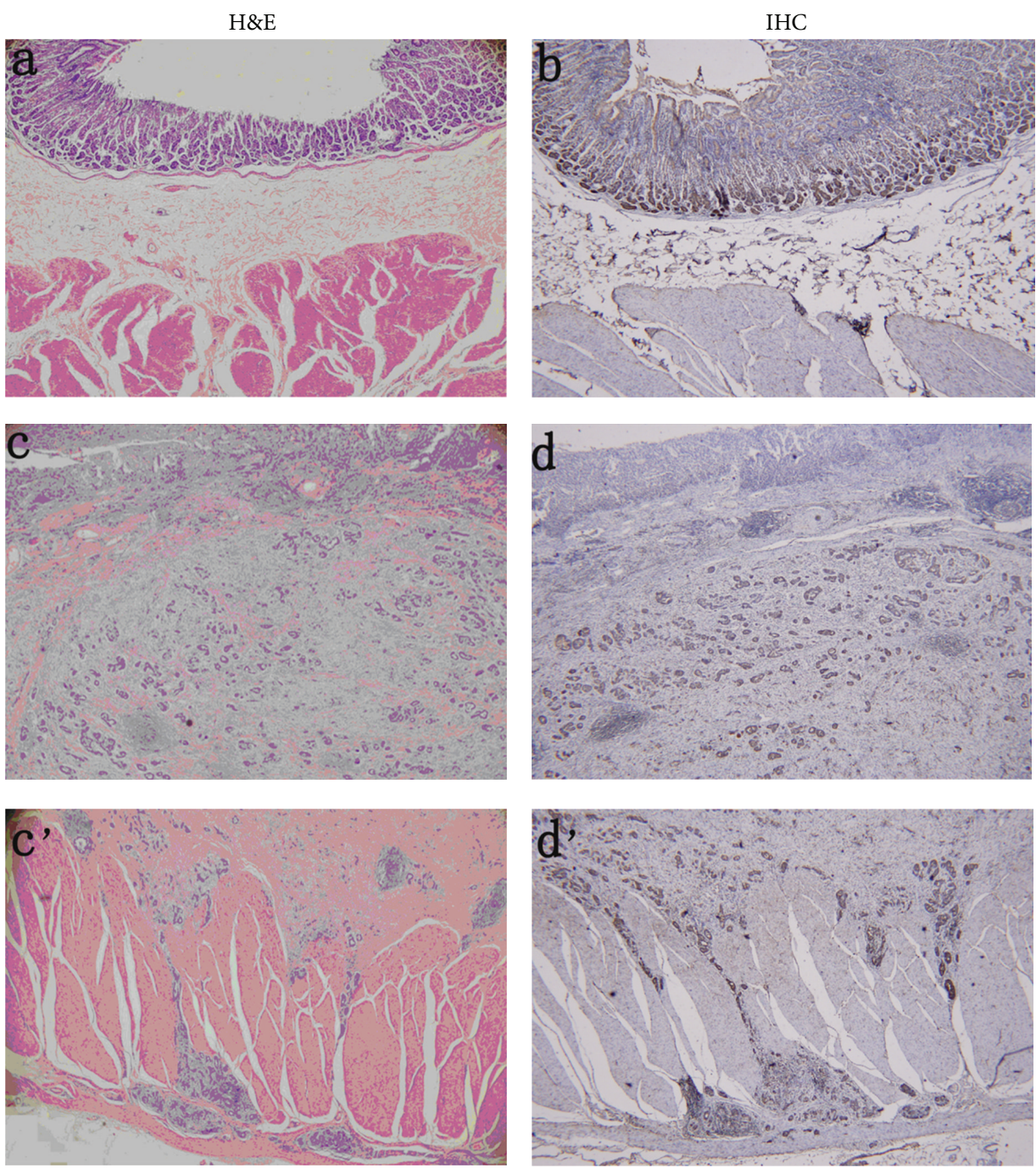

FIGURE 4: Immunohistochemistry and hematoxylin and eosin staining of Nell-1 protein expression (a, b) normal tissues; (c, d) mucosal layer of tumour tissues; (c', d') muscular layer of tumour tissues.

involving various genetic and epigenetic changes [33]. The relationship between Nell-1 methylation and Nell-1 protein expression requires further confirmation. Transcriptional silencing of the Nell-1 promoter is an early and common event in human EAC [23] and colon tumorigenesis [22]. Increased methylation of Nell-1 may play a role in other cancers [34]. Our results indicate that the methylation level of the Nell1 promoter is related to the spread of gastric cancer cells. Nell-1 expression was detected in normal and gastric cancer tissues, suggesting a physiological role in normal gastric tissues. It will be interesting to investigate the correlation of Nell-1 promoter methylation with the transformation of gastric cancer cells and cancer prevention.

\section{Conclusions}

MALDI-TOF MS is a useful tool for the analysis of DNA methylation. Methylation of the Nell-1 promoter is a common event in gastric cancer compared with normal tissue. Nell-1 promoter methylation reduced the expression of Nell-1 in gastric cancer tissues, as determined by a lower intensity of IHC staining, with expansion to the muscle layer. This suggests that Nell-1 can be used as a biomarker for the diagnosis of gastric cancer.

\section{Abbreviations \\ MALDI-TOF MS: Matrix-assisted laser desorption/ionization time-of-flight mass spectrometry \\ IHC: Immunohistochemistry \\ H\&E: Hematoxylin and eosin.}

\section{Conflict of Interests}

The authors declare that there were no competing financial interests and no conflict of interests regarding the publication of this paper. 


\section{Acknowledgments}

Funding for this study was provided by the National Natural Science Foundation of China (81200762) and Heilongjiang Province Natural Science Foundation (ZD200920). The authors gratefully acknowledge the assistance from Bioyong technologies Inc. and Beijing Compass Biotechnology Co., Ltd., for technical support.

\section{References}

[1] X. L. Chen, X. Z. Chen, C. Yang et al., "Docetaxel, Cisplatin and Fluorouracil (DCF) regimen compared with non-taxanecontaining palliative chemotherapy for gastric carcinoma: a systematic review and meta-analysis," PLoS ONE, vol. 8, no. 4, Article ID e60320, 2013.

[2] R. Siegel, D. Naishadham, and A. Jemal, "Cancer statistics, 2012," CA Cancer Journal for Clinicians, vol. 62, no. 1, pp. 10-29, 2012.

[3] H. H. Hartgrink, E. P. Jansen, N. C. van Grieken, and C. J. van de Velde, “Gastric cancer," The Lancet, vol. 374, no. 9688, pp. 477-490, 2009.

[4] A. Jemal, R. Siegel, E. Ward, T. Murray, J. Xu, and M. J. Thun, "Cancer statistics, 2007," Ca: Cancer Journal for Clinicians, vol. 57, no. 1, pp. 43-66, 2007.

[5] I. Songun, H. Putter, E. M. K. Kranenbarg, M. Sasako, and C. J. van de Velde, "Surgical treatment of gastric cancer: 15-year follow-up results of the randomised nationwide Dutch D1D2 trial," The Lancet Oncology, vol. 11, no. 5, pp. 439-449, 2010.

[6] A. B. Mariotto, K. Robin Yabroff, Y. Shao, E. J. Feuer, and M. L. Brown, "Projections of the cost of cancer care in the United States: 2010-2020," Journal of the National Cancer Institute, vol. 103, no. 2, pp. 117-128, 2011.

[7] L. Pan, M. He, J. Ma et al., "Phase and size controllable synthesis of $\mathrm{NaYbF}_{4}$ nanocrystals in oleic acid/ ionic liquid twophase system for targeted fluorescent imaging of gastric cancer," Theranostics, vol. 3, no. 3, pp. 210-222, 2013.

[8] P. A. Jones and S. B. Baylin, "The Epigenomics of Cancer," Cell, vol. 128, no. 4, pp. 683-692, 2007.

[9] P. Vogiatzi, C. Vindigni, F. Roviello, A. Renieri, and A. Giordano, "Deciphering the underlying genetic and epigenetic events leading to gastric carcinogenesis," Journal of Cellular Physiology, vol. 211, no. 2, pp. 287-295, 2007.

[10] S. H. Song, S. W. Han, and Y. J. Bang, "Epigenetic-Based therapies in cancer: progress to date," Drugs, vol. 71, no. 18, pp. 2391-2403, 2011.

[11] B.-G. Jang and W. H. Kim, "Molecular pathology of gastric carcinoma," Pathobiology, vol. 78, no. 6, pp. 302-310, 2011.

[12] T. Tsuchiya, G. Tamura, K. Sato et al., "Distinct methylation patterns of two APC gene promoters in normal and cancerous gastric epithelia," Oncogene, vol. 19, no. 32, pp. 3642-3646, 2000.

[13] A. S. Fleisher, M. Esteller, G. Tamura et al., "Hypermethylation of the hMLH1 gene promoter is associated with microsatellite instability in early human gastric neoplasia," Oncogene, vol. 20, no. 3, pp. 329-335, 2001.

[14] Q.-L. Li, K. Ito, C. Sakakura et al., "Causal relationship between the loss of RUNX3 expression and gastric cancer," Cell, vol. 109, no. 1, pp. 113-124, 2002.

[15] A. Wanajo, A. Sasaki, H. Nagasaki et al., "Methylation of the calcium channel-related gene, CACNA2D3, is frequent and a poor prognostic factor in gastric cancer," Gastroenterology, vol. 135, no. 2, pp. 580-e3, 2008.
[16] J. Yu, Q. Tao, Y. Y. Cheng et al., "Promoter methylation of the $\mathrm{Wnt} / \beta$-catenin signaling antagonist Dkk-3 is associated with poor survival in gastric cancer," Cancer, vol. 115, no. 1, pp. 49-60, 2009.

[17] X. Chen, X. Cao, W. Dong et al., "Cystatin M expression is reduced in gastric carcinoma and is associated with promoter hypermethylation," Biochemical and Biophysical Research Communications, vol. 391, no. 1, pp. 1070-1074, 2010.

[18] H. Zhao, Q. Li, J. Wang et al., "Frequent epigenetic silencing of the folate-metabolising gene cystathionine-beta-synthase in gastrointestinal Cancer," PLoS ONE, vol. 7, no. 11, Article ID e49683, 2012.

[19] D. F. Peng, T. L. Hu, B. G. Schneider, Z. Chen, Z. K. Xu, and W. El-Rifai, "Silencing of glutathione peroxidase 3 through DNA hypermethylation is associated with lymph node metastasis in gastric carcinomas," PLoS ONE, vol. 7, no. 10, Article ID e46214, 2012.

[20] R. Mazzolini, P. Rodrigues, S. Bazzocco et al., "Brush border myosin Ia inactivation in gastric but not endometrial tumors," International Journal of Cancer, vol. 132, no. 8, pp. 1790-1799, 2013.

[21] T. K. Watanabe, T. Katagiri, M. Suzuki et al., "Cloning and characterization of two novel human cDNAs (NELL1 and NELL2) encoding proteins with six EGF-like repeats," Genomics, vol. 38, no. 3, pp. 273-276, 1996.

[22] Y. Mori, K. Cai, Y. Cheng et al., "A genome-wide search identifies epigenetic silencing of somatostatin, tachykinin-1, and 5 other genes in colon cancer," Gastroenterology, vol. 131, no. 3, pp. 797808, 2006.

[23] Z. Jin, Y. Mori, J. Yang et al., "Hypermethylation of the nellike 1 gene is a common and early event and is associated with poor prognosis in early-stage esophageal adenocarcinoma," Oncogene, vol. 26, no. 43, pp. 6332-6340, 2007.

[24] M. Ehrich, M. R. Nelson, P. Stanssens et al., "Quantitative highthroughput analysis of DNA methylation patterns by basespecific cleavage and mass spectrometry," Proceedings of the National Academy of Sciences of the United States of America, vol. 102, no. 44, pp. 15785-15790, 2005.

[25] P. Stanssens, M. Zabeau, G. Meersseman et al., "Highthroughput MALDI-TOF discovery of genomic sequence polymorphisms," Genome Research, vol. 14, no. 1, pp. 126-133, 2004.

[26] M. Ehrich, J. Turner, P. Gibbs et al., "Cytosine methylation profiling of cancer cell lines," Proceedings of the National Academy of Sciences of the United States of America, vol. 105, no. 12, pp. 4844-4849, 2008.

[27] P. Hudler, "Genetic aspects of gastric cancer instability," The Scientific World Journal, vol. 2012, Article ID 761909, 10 pages, 2012.

[28] R. J. Klose and A. P. Bird, "Genomic DNA methylation: the mark and its mediators," Trends in Biochemical Sciences, vol. 31, no. 2, pp. 89-97, 2006.

[29] M. L. Bellido, R. Radpour, O. Lapaire et al., "MALDI-TOF mass array analysis of RASSF1A and SERPINB5 methylation patterns in human placenta and plasma," Biology of Reproduction, vol. 82, no. 4, pp. 745-750, 2010.

[30] J. G. Herman and S. B. Baylin, "Gene silencing in cancer in association with promoter hypermethylation," The New England Journal of Medicine, vol. 349, no. 21, pp. 2042-2054, 2003.

[31] X. Zou, J. Shen, F. Chen et al., "NELL-1 binds to APR3 affecting human osteoblast proliferation and differentiation," FEBS Letters, vol. 585, no. 15, pp. 2410-2418, 2011. 
[32] K. Ting, H. Vastardis, J. B. Mulliken et al., "Human NELL-1 expressed in unilateral coronal synostosis," Journal of Bone and Mineral Research, vol. 14, no. 1, pp. 80-89, 1999.

[33] A. Rocco, D. Compare, and G. Nardone, "Cancer stem cell hypothesis and gastric carcinogenesis: experimental evidence and unsolved questions," World Journal of Gastrointestinal Oncology, vol. 4, pp. 54-59, 2012.

[34] Y. Mori, K. Cai, Y. Cheng et al., "A genome-wide search identifies epigenetic silencing of somatostatin, tachykinin-1, and 5 other genes in colon cancer," Gastroenterology, vol. 131, no. 3, pp. 797808, 2006. 

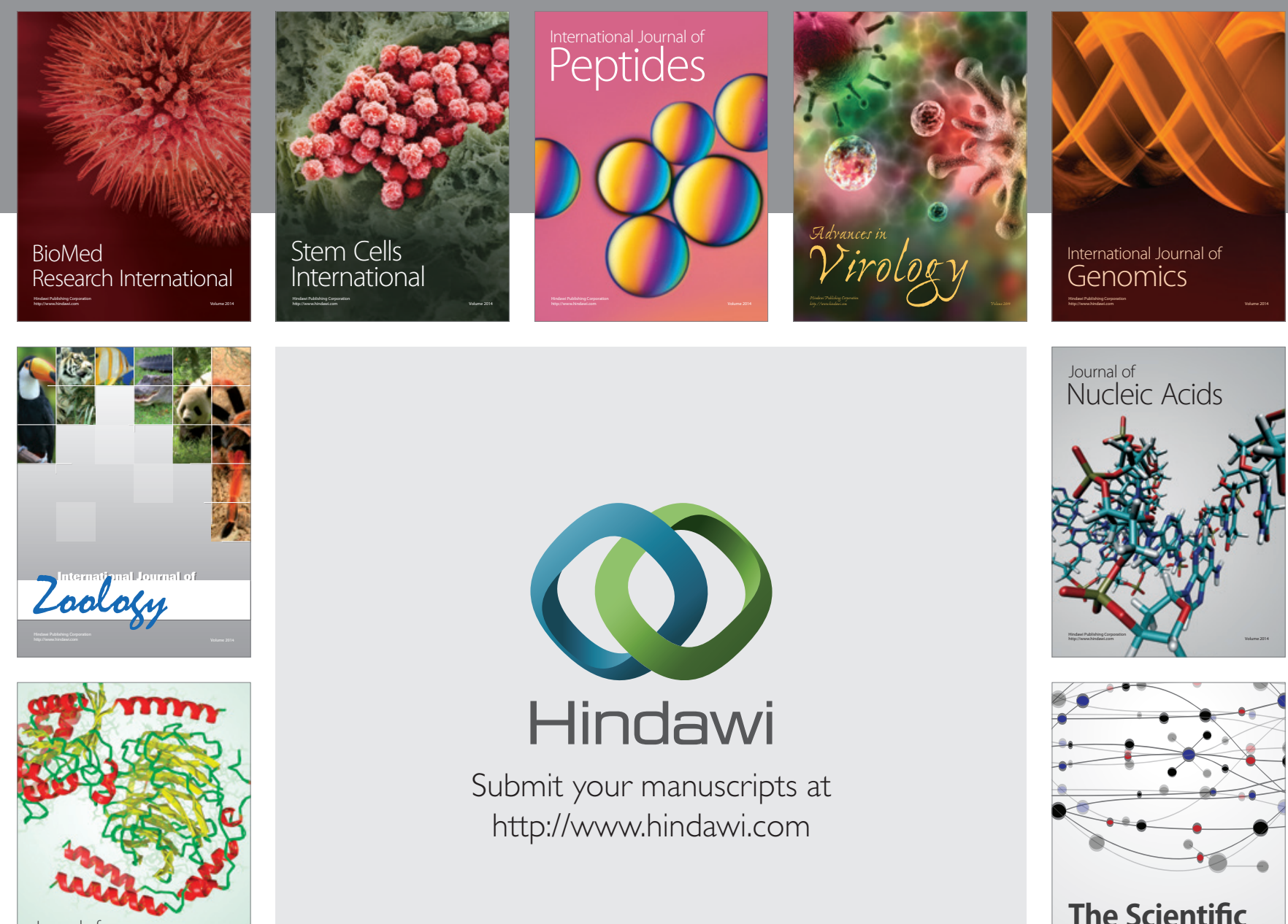

Submit your manuscripts at

http://www.hindawi.com

Journal of
Signal Transduction
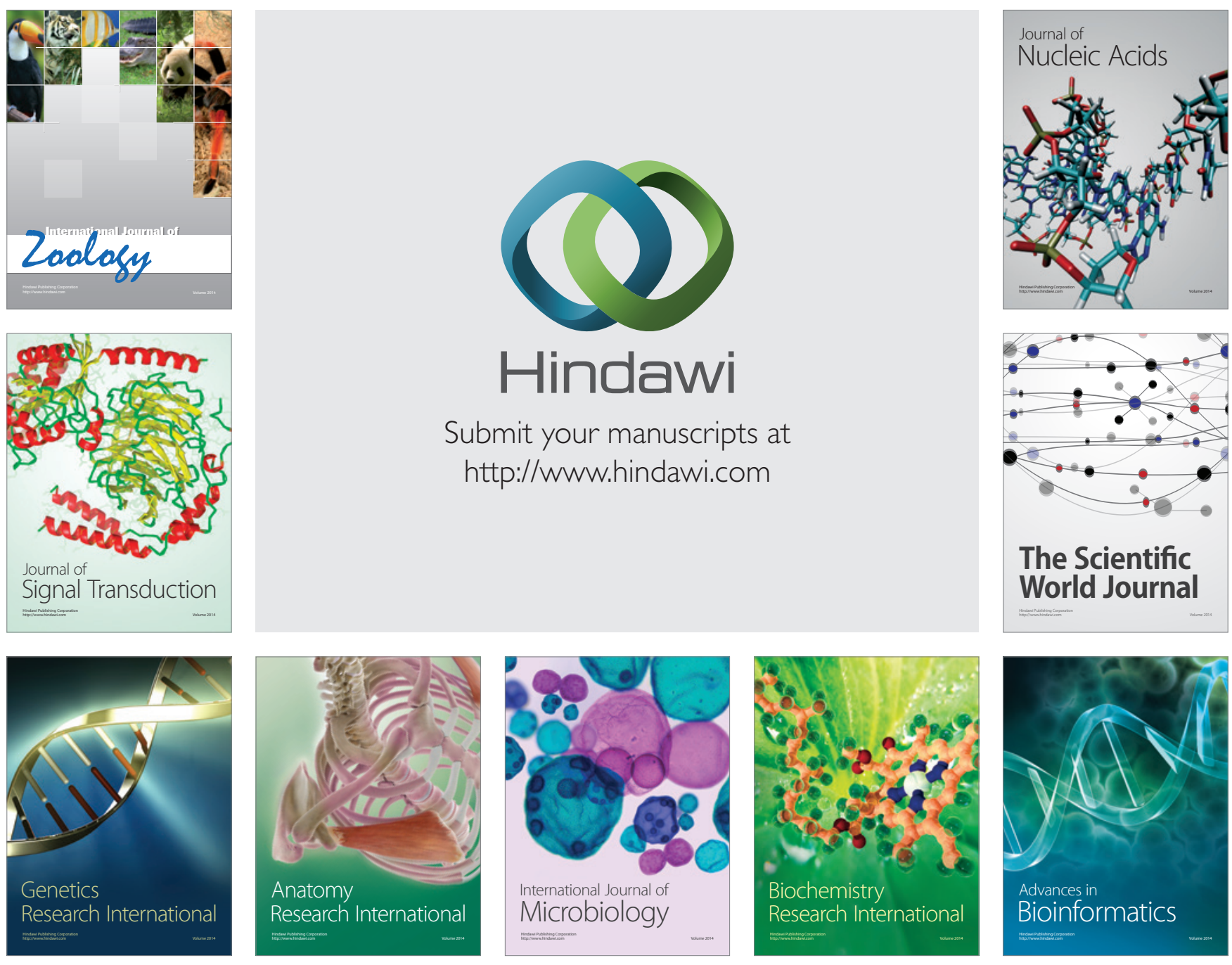

The Scientific World Journal
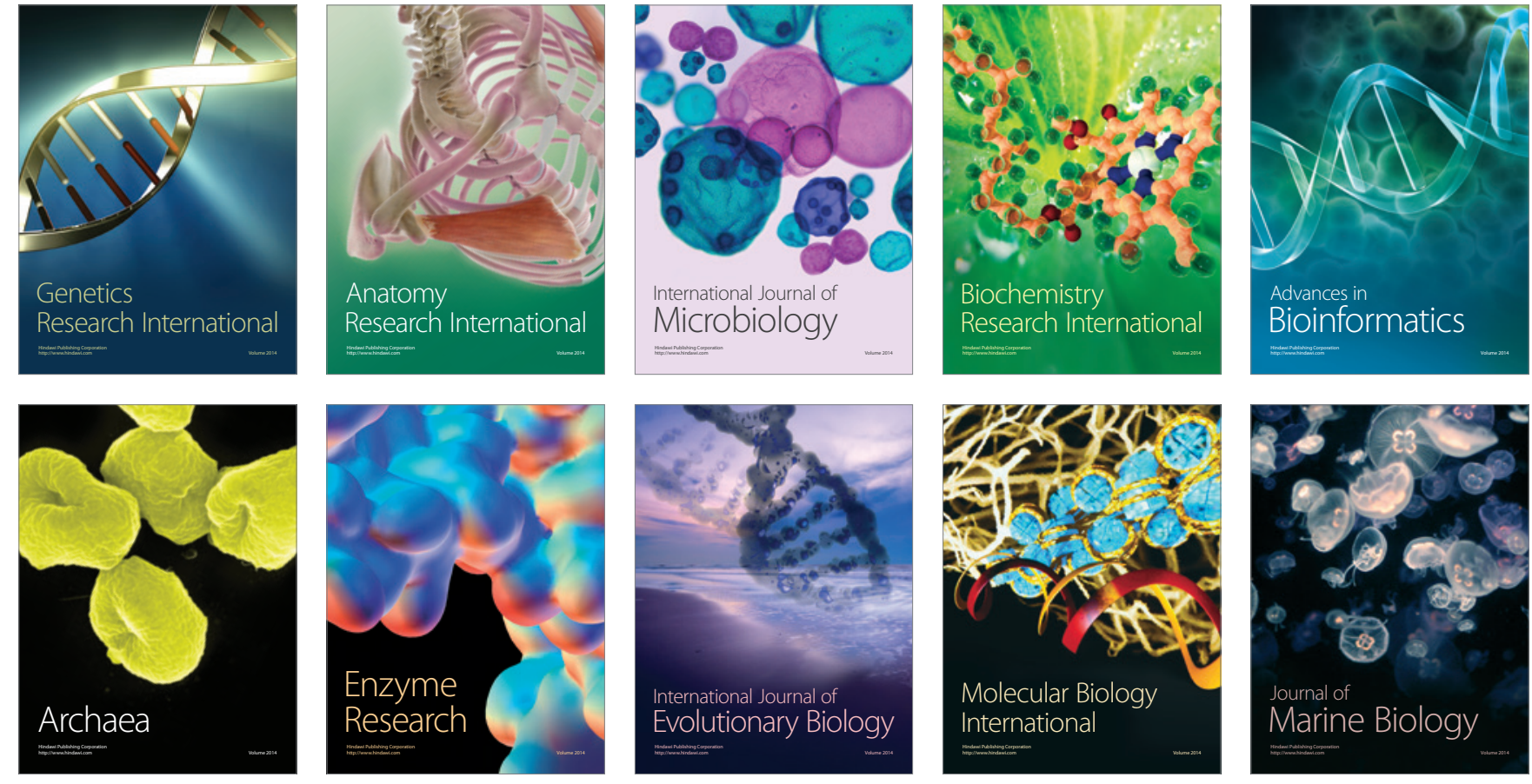